\title{
Changes in peak expiratory flow indices as a proxy for changes in bronchial hyperresponsiveness
}

\author{
W.R. Douma*, H.A.M. Kerstjens*, C.M. Roos**, G.H. Koëter*, D.S. Postma*, \\ and the Dutch Chronic Non-Specific Lung Disease study group
}

\begin{abstract}
Changes in peak expiratory flow indices as a proxy for changes in bronchial hyperresponsiveness. W.R. Douma, H.A.M. Kerstjens, C.M. Roos, G.H. Koëter, D.S. Postma, and the Dutch Chronic Non-Specific Lung Disease study group. (C)ERS Journals Ltd 2000.

ABSTRACT: Guidelines for asthma management advocate home peak expiratory flow (PEF) monitoring. It is commonly stated that PEF variability is a good proxy of bronchial hyperresponsiveness (BHR), a hallmark of asthma. However, this has hardly been tested longitudinally, as required to monitor asthma. This study assesses which PEF index correlates best with BHR longitudinally and whether the correlation improves when correcting PEF values for the known nonlinearity of mini-Wright PEF meters.
\end{abstract}

Every 6 months, for a period of 2 yrs, PEF diary cards were filled in and BHR to histamine was tested in 104 patients with BHR and reversible airways obstruction, who started treatment with bronchodilators with $(n=33)$ or without $(n=71)$ inhaled corticosteroids. Within each subject, PEF indices and BHR were correlated longitudinally.

The highest median correlation coefficients were obtained in the group of patients using inhaled corticosteroids. The PEF indices providing the best correlation with BHR were: mean PEF bronchodilator response $(\rho=-0.50)$ and within-day variation $(\%$ mean or \% maximum) (with postbronchodilator values, $\rho=-0.50$; without postbronchodilator values, $\rho=-\mathbf{0 . 4 0}$ ). Using PEF data corrected for the nonlinearity of the PEF meters did not result in higher correlation coefficients.

Since current guidelines on asthma management recommend only bronchodilators on demand, the most useful peak expiratory flow index for reflecting bronchial hyperresponsiveness longitudinally is mean within-day peak expiratory flow variation ( $\%$ mean or \% maximum) (without postbronchodilator values). Since the correlation coefficients are not very strong, the authors suggest that peak expiratory flow measurements are not used as a proxy for bronchial hyperresponsiveness longitudinally but as a measurement in its own right. The use of corrections of peak expiratory flows for the nonlinearity of mini-Wright peak expiratory flow meters does not improve the correlation between peak expiratory flow and bronchial hyperresponsiveness.

Eur Respir J 2000; 16: 220-225.
*Dept of Pulmonology, University Hospital Groningen, Groningen and **Dept of Pulmonology, University Hospital Amsterdam, Amsterdam, the Netherlands.

Correspondence: D.S. Postma

University Hospital Groningen

Dept of Pulmonology

Hanzeplein 1

9713 GZ Groningen

the Netherlands

Fax: 31503619320

\section{Keywords: Asthma}

bronchial hyperresponsiveness

peak expiratory flow

Received: August 261998

Accepted after revision March 132000

This study was made possible by grants from the Netherlands' Health Research Promotion Program (SGO) and Glaxo. Medication was supplied by Astra Pharmaceuticals, Zoetermeer, Netherlands, Boehringer Ingelheim, Alkmoor, Netherlands and GlaxoWellcome, Zeist, Netherlands.
Peak expiratory flow (PEF) measurements are broadly advocated as a tool for monitoring asthma [1], being useful as an indicator of the diagnosis [2,3], state of the disease [3], necessity to start or change therapy [4], and response to treatment [5]. Increased PEF variation is thought by many experts to reflect the degree of bronchial hyperresponsiveness (BHR) [6]. Several cross-sectional studies have indeed shown moderate-to-strong correlations between PEF indices and BHR $[2,7,8]$. However, if serial PEF measurements are to be used in patients to reflect BHR in order to monitor asthma severity, the measure of PEF variation should correlate with changes in BHR within patients longitudinally, instead of between patients cross-sectionally. Hardly any such longitudinal analyses have been performed $[9,10]$.

Although the performance of repetitive home PEF measurements is recommended in all guidelines for asthma management, there is little clarity as to which time of day and how frequently PEF should be measured or how to express the results. Mean PEF variation over the day expressed as percentage of the maximum, the mean, and the personal best are but a few of the expressions encountered [8]. In this study, the longitudinal relationship between these and other PEF indices and BHR were investigated in a 2-yr study including the effects of different treatment regimens, i.e. the combination of inhaled bronchodilators (BDs) and corticosteroids or inhaled BDs alone [11].

An additional point which was addressed is the recent insight provided by MiLler et al. [12] that conventional PEF meters such as the mini-Wright PEF meter consistently overread in the midflow ranges and underread at lower and higher levels. The relationship between PEF indices and BHR could be influenced by this. Therefore, the correction factor for this nonlinearity of the PEF meters was also used [13].

The aims of the study were: 1) to determine which PEF index correlates best longitudinally in two different groups of patients: patients with BHR and reversible airways 
obstruction treated with BDs in combination with inhaled corticosteroids (ICS+) and patients treated with BDs alone (ICS-); 2) to determine whether the correlation between $\mathrm{PEF}$ and BHR is better when correcting PEFs for the nonlinearity of the PEF meters; and 3) to determine whether the PEF index that correlates best with BHR longitudinally is different from that which correlates best cross-sectionally.

\section{Methods}

Data from a randomized double-blind multicentre clinical study initiated by the Dutch government were used. The main goal of this study was to compare the effect of three treatment regimens ( $\beta_{2}$-agonist plus either placebo, anticholinergic agent or corticosteroid, all by inhalation) on the long-term course and outcome of chronic nonspecific lung diseases (asthma and chronic obstructive pulmonary diseases (COPD)) [11]. Two hundred and seventy-four patients, 18-60 yrs old, with moderate-to-severe bronchoconstriction and BHR were included at six university pulmonary outpatient clinics. The forced expiratory volume in one second (FEV1) needed to be $>1.2 \mathrm{~L}$, and 4.51.64 residual standard deviation (RSD, being the SD of the prediction equation) below the predicted value, or the FEV1/inspiratory vital capacity $>1.64$ RSD below the predicted level. The provocative concentration of inhaled histamine producing a $20 \%$ fall in FEV1 (PC20) needed to be $<8 \mathrm{mg} \cdot \mathrm{mL}^{-1}$. Patients with a history of occupational asthma or other serious diseases (e.g. tuberculosis, myocardial infarction or malignancies) were excluded. Subjects were not allowed to use oral corticosteroids, $\beta$-blockers, nitrates, anticoagulants or antibiotics on a maintenance base. The study protocol was approved by the Medical Ethics Committees of all participating centres. All patients gave written informed consent.

For the analyses presented in this report, those patients with BHR and significant reversibility to a $\beta_{2}$-agonist (change in $(\Delta) \mathrm{FEV} 1 \geq 9 \%$ pred) were selected from the total group to reflect asthmatic patients [14]. The results in the patients receiving BDs in combination with inhaled corticosteroids were compared with the results in patients receiving $\mathrm{BDs}$ alone.

\section{Measurements}

FEV1 and PC20 were measured at baseline and every 6 months during the study. During a period of 2 weeks before each visit, patients recorded PEF values at home, three times daily. Measurements were made only during clinically stable periods and not within 4 weeks after termination of a course of prednisolone. BDs were discontinued 8 $\mathrm{h}$ before each test (no long-acting BD treatment was used). Because of the known diurnal variation in $\mathrm{FEV} 1$ and $\mathrm{PC}_{20}$, measurements were scheduled within $2 \mathrm{~h}$ of the measurement time on the first day.

\section{Allergy}

Atopy was assessed at baseline by intradermal skin testing using 12 common aeroallergens. Patients were categorized as allergic when they showed a positive reaction to one or more allergens [15].

\section{Lung function}

FEV1 measurement was performed with calibrated water-sealed spirometers according to standardized guidelines [16]. At least three reproducible values (i.e. with $<5 \%$ difference among the recordings) were obtained; the highest value was used in the analyses. At baseline, BD response measurement was performed by FEV1 testing before and $20 \mathrm{~min}$ after administration of 1,000 $\mu \mathrm{g}$ terbutaline from a metered dose inhaler through a $750-\mathrm{mL}$ spacer device (Nebuhaler; Astra Pharmaceuticals, Rijswijk, the Netherlands). The BD response was expressed as a percentage of the predicted value.

\section{Histamine challenge test}

Histamine challenge tests were performed using a 2-min tidal breathing method [17]. Aerosols were delivered from a calibrated DeVilbiss 646 nebulizer (DeVilbiss Health Inc., Somerset, PA, USA). The solution output was 0.13 $\mathrm{mL} \cdot \mathrm{min}^{-1}$. Results were expressed as PC20. For analysis, a value of 0.015 was assigned to each patient who responded to saline or the lowest concentration of histamine $(0.03$ $\left.\mathrm{mg} \cdot \mathrm{mL}^{-1}\right)$. During the follow-up, a value of $64 \mathrm{mg} \cdot \mathrm{mL}^{-1}$ was assigned when FEV 1 decreased by $<20 \%$ from baseline using the highest concentration of histamine (32 $\left.\mathrm{mg} \cdot \mathrm{mL}^{-1}\right)$.

\section{Peak expiratory flow measurements}

After standardized instruction at the outpatient clinic, patients recorded PEF at home, 14 days before each visit, using a mini Wright peak flow meter (Clement Clarke International Ltd., London, UK). PEF measurements were performed three times daily, directly after rising (both before and $10 \mathrm{~min}$ after study medication) and in the afternoon (before the evening meal) and the highest value of three was recorded at each time.

\section{Peak expiratory flow indices calculated for each period} of 2 weeks

The PEF indices calculated for each period of 2 weeks with the different means of expression are presented schematically in table 1 .

\section{Correction of peak expiratory flow values}

Because of the inaccuracy of the PEF meters, the PEF values were corrected using the following formula: 0.0009PEF ${ }^{2}+0.373 \mathrm{PEF}+47.4$ [13]. All above PEF indices were also determined with the corrected PEF values.

\section{Data analysis}

Peak flow cards were used only when at least nine of the 14 days were filled in. The analyses were limited to those patients with acceptable diary cards at baseline and with a follow up of $\geq 2$ yrs. Calculations with PC20 were performed using base 2 logarithmic values since this reflects 
Table 1. - Peak expiratory flow (PEF) indices calculated for each period of 2 weeks*

\begin{tabular}{|c|c|c|c|c|c|c|c|}
\hline \multirow{2}{*}{ PEF indices } & \multicolumn{7}{|c|}{ Means of expression } \\
\hline & Absolute & $\%$ pred & $\%$ mean & $\begin{array}{c}\% \text { max* } \\
(2 \text { weeks })\end{array}$ & $\begin{array}{l}\% \text { recent } \\
\text { best } * *\end{array}$ & $\begin{array}{c}\% \text { max } \\
\text { day value }\end{array}$ & $\begin{array}{l}\% \text { pre-BD } \\
\text { PEFa.m. }\end{array}$ \\
\hline \multirow{2}{*}{\multicolumn{8}{|c|}{$\begin{array}{l}\text { Pre-BD PEFa.m., post-BD PEFa.m. and } \\
\text { PEFp.m. }\end{array}$}} \\
\hline & & & & & & & \\
\hline Mean & $\mathrm{X}$ & $\mathrm{X}$ & & $\mathrm{X}$ & \multirow{3}{*}{$\mathrm{x}$} & & \\
\hline Minimum & $\mathrm{x}$ & & & & & & \\
\hline Maximum & $\mathrm{x}$ & & & & & & \\
\hline \multicolumn{8}{|c|}{ Bronchodilator response $^{+}$} \\
\hline Mean & $\mathrm{x}$ & $\mathrm{x}$ & $\mathrm{x}$ & & & & $\mathrm{x}$ \\
\hline \multicolumn{8}{|c|}{ PEF variability } \\
\hline \multicolumn{8}{|c|}{ Within-day variation ${ }^{\#}$} \\
\hline Mean & & $\mathrm{x}$ & $\mathrm{x}$ & & & $\mathrm{x}$ & \\
\hline $\begin{array}{l}\text { DTD }^{\S} \text { Pre-BD PE } \\
\text { and PEFp.m. }\end{array}$ & & & & & & & \\
\hline Mean & & $\mathrm{X}$ & $\mathrm{x}$ & $\mathrm{x}$ & & & \\
\hline \multicolumn{8}{|l|}{ SD } \\
\hline Pre-BD PEFa.m. & & & $\mathrm{x}$ & & & & \\
\hline Post-BD PEFa.m. & & & $\mathrm{x}$ & & & & \\
\hline PEFp.m. & & & $\mathrm{x}$ & & & & \\
\hline PEFday & & & $\mathrm{x}$ & & & & \\
\hline
\end{tabular}

*: each day three PEF measurements were recorded (in the morning (a.m.), before and after bronchodilator (BD) use, and in the afternoon(p.m.)).*: measured at a specific time of day pre-BD; **: highest pre-BD PEFa.m. value of the 2 weeks (only measured for the pred-BD PEFa.m.). ${ }^{+}$: post-BD-pre-BD PEF; ${ }^{\#}$ : highest-lowest daytime PEF (with or without post-BD values); ${ }^{\text {s }}$ : PEF of day $(x+1)-P E F$ of day $\mathrm{x}$; : both pre-BD PEFa.m. and PEFp.m.. \% pred: percentage of the predicted value; max: maximum; DTD: day-to-day variation.

doubling concentrations and normalized distributions. Normality of distributions was assessed with Kolmogorov-Smirnov tests in order to decide whether to apply parametric (Pearson correlation, unpaired t-test) or nonparametric techniques (Spearman rank correlation, Mann-Whitney U-test). Chi-squared tests were used for dichotomous variables. Two sided $p$-values of $<0.05$ were considered significant. For the longitudinal analysis over a period of 2 yrs, individual Spearman rank correlations between BHR and each PEF index were calculated. These correlation coefficients are summarized as medians within the interquartile ranges. The cross-sectional correlation coefficients for the different $\mathrm{PEF}$ indices with BHR are presented as Pearson correlations.

\section{Results}

Of the 274 patients who were enrolled in the study, 91 were randomly assigned to the ICS+ group, and 183 to the ICS- group. For this 2-yr study, patients with BHR and significant reversibility to a $\beta_{2}$-agonist $(\triangle \mathrm{FEV} 1 \geq 9 \%$ pred), and a complete set of PEF diary records, were selected. The baseline characteristics of patients treated with BDs in combination with inhaled corticosteroids $(n=33)$ and patients treated with BDs alone $(\mathrm{n}=71)$ are presented in table 2. There were no significant differences between the 33 subjects of the ICS+ group and the 71 subjects of the ICSgroup.

\section{Longitudinal analyses}

Table 3 shows the median (within-subject) correlation coefficients and their interquartile ranges of the PEF indices and BHR to histamine. These correlation coeffi- cients are weak to moderate. Groups of PEF indices with even weaker correlation coefficients are not presented: post-BD morning PEF (PEFa.m.), afternoon PEF, day-today variation, and the SD of 2 -weeks PEFs.

In the ICS + group, the highest correlation coefficients were obtained with the PEF indices reflecting $\mathrm{BD}$ response

Table 2. - Baseline characteristics of patients according to treatment and reversible airways obstruction

\begin{tabular}{|c|c|c|}
\hline & ICS+ & ICS- \\
\hline Patients $n$ & 33 & 71 \\
\hline Male sex n $(\%)$ & $21(63.6)$ & $45(63.4)$ \\
\hline Age yrs & $40 \pm 12.3$ & $37 \pm 12.8$ \\
\hline \multicolumn{3}{|l|}{ Smoking habit n (\%) } \\
\hline Neversmoker & $8(24.2)$ & $30(42.3)$ \\
\hline Exsmoker & $11(33.3)$ & $25(35.2)$ \\
\hline Current smoker & $14(42.4)$ & $16(22.5)$ \\
\hline Allergic n (\%) & $26(78.8)$ & $58(81.7)$ \\
\hline Pre-BD FEV1 \% pred & $63.4 \pm 13.3$ & $60.6 \pm 15.3$ \\
\hline$\Delta \mathrm{FEV} 1$ post-terbutaline $\%$ pred & $17.3 \pm 5.5$ & $17.5 \pm 6.0$ \\
\hline $\log _{2} \mathrm{PC} 20 \mathrm{mg} \cdot \mathrm{mL}^{-1}$ & $-1.94 \pm 1.90$ & $-2.54 \pm 2.24$ \\
\hline Geometric mean PC20 $\mathrm{mg} \cdot \mathrm{mL}^{-1}$ & 0.26 & 0.17 \\
\hline Pre-BD PEFa.m.L.min ${ }^{-1}$ & $403 \pm 141$ & $376 \pm 98$ \\
\hline Post-BD PEFa.m.L. $\min ^{-1}$ & $476 \pm 131$ & $447 \pm 101$ \\
\hline PEFp.m.L.min ${ }^{-1}$ & $465 \pm 135$ & $434 \pm 97$ \\
\hline PEF amplitude $\%$ mean & $17.8 \pm 11.2$ & $17.5 \pm 9.0$ \\
\hline PEF amplitude \% max & $15.5 \pm 8.9$ & $15.4 \pm 7.2$ \\
\hline
\end{tabular}

Data are presented as mean \pm SD. ICS + : group treated with inhaled corticosteroids and a $\beta_{2}$-agonist; ICS-: group treated without inhaled corticosteroids, but with a $\beta_{2}$-agonist and/or an anticholinergic agent. BD: bronchodilator; FEV1: forced expiratory volume in one second; $\Delta$ : change in; \% pred: percentage of the predicted value; $\mathrm{PC} 20$ : provocative concentration of inhaled histamine producing a $20 \%$ fall in FEV1; PEFa.m.: morning peak expiratory flow; PEFp.m.: afternoon peak expiratory flow; max: maximum; amplitude: within-day variation (highest-lowest). 
Table 3. - Within-subject Spearman's rank correlation coefficients for longitudinal relations between peak expiratory flow (PEF) indices and bronchial hyperresponsiveness by treatment

\begin{tabular}{lccc}
\hline & ICS+ & ICS- & ICS+ Corrected PEFs* \\
\hline Mean pre-BD PEFa.m. & $0.40(-0.25-0.60)$ & $0.22(-0.30-0.60)$ & $0.33(-0.25-0.65)$ \\
\% pred & $0.33(-0.25-0.65)$ & $0.10(-0.50-0.60)$ & $0.33(-0.25-0.65)$ \\
\% max & $0.30(0.00-0.69)$ & $0.30(-0.20-0.50)$ & $0.30(0.00-0.70)$ \\
Min pre-BD PEFa.m. & $0.32(-0.23-0.68)$ & $0.30(-0.21-0.67)$ & $0.30(-0.20-0.68)$ \\
\% recent best & $0.30(-0.12-0.70)$ & $0.30(0.00-0.70)$ & $0.30(-0.12-0.60)$ \\
Max pre-BD PEFa.m. & $0.40(-0.38-0.75)$ & $0.05(-0.40-0.67)$ & $0.30(-0.33-0.70)$ \\
Mean bronchodilator response & $-0.40(-0.60-0.05)$ & $-0.30(-0.70-0.08)$ & $-0.30(-0.45-0.10)$ \\
\% mean & $-0.50(-0.80--0.10)$ & $-0.30(-0.63-0.10)$ & $-0.50(-0.75-0.10)$ \\
\% pred & $-0.40(-0.70--0.09)$ & $-0.30(-0.60-0.08)$ & $-0.30(-0.60-0.20)$ \\
\% pre-BD PEFa.m. & $-0.50(-0.80--0.10)$ & $-0.30(-0.60-0.10)$ & $-0.50(-0.70-0.10)$ \\
Mean PEF amplitude (-BD) & & & \\
\% mean & $-0.40(-0.89-0.10)$ & $-0.30(-0.70-0.20)$ & $-0.33(-0.84--0.10)$ \\
\% pred & $-0.33(-0.80-0.05)$ & $-0.30(-0.70-0.10)$ & $-0.33(-0.80-0.15)$ \\
\% max & $-0.40(-0.89--0.10)$ & $-0.30(-0.70-0.20)$ & $-0.50(-0.84-0.10)$ \\
Mean PEF amplitude (+BD) & & & \\
\% mean & $-0.50(-0.70-0.05)$ & $-0.30(-0.70-0.10)$ & $-0.40(-0.70--0.05)$ \\
\% pred & $-0.40(-0.60-0.10)$ & $-0.30(-0.67-0.00)$ & $-0.30(-0.70-0.10)$ \\
\% max & $-0.50(-0.70-0.09)$ & $-0.30(-0.70-0.10)$ & $-0.40(-0.70-0.09)$ \\
\hline
\end{tabular}

Data are presented as median (interquartile range). *: for nonlinearity of mini-Wright PEF meter. ICS+: group treated with inhaled corticosteroids and a $\beta_{2}$-agonist; ICS-: group treated without inhaled corticosteroids, but with a $\beta_{2}$-agonist and/or an anticholinergic agent. BD: bronchodilator; PEFa.m.: morning PEF; \% pred: percentage of the predicted value; max: maximum; min: minimum; -BD: not including post-BD PEFs; +BD: including post-BD PEFs; amplitude: within-day variation (highest-lowest).

(\% mean) $(\rho=-0.50)$ and within-day variation $(\%$ mean $)$ $(\rho=-0.50$ with post-BD values, $\rho=-0.40$ without post-BD values). In the ICS-group, the highest absolute correlation coefficients were 0.30 , also for the three above-mentioned indices.

The last column of table 3 shows the median correlation coefficients between PEF indices and BHR, obtained with PEF data corrected for the nonlinearity of the PEF meters, in the 33 subjects of the ICS+ group. These correlations were no better than those obtained with the "uncorrected" PEF data (first column).

\section{Cross-sectional analyses}

Table 4 shows the correlation coefficients of the crosssectional analyses at the end of the 2-yrs treatment. The same indices as for the longitudinal analyses are presented, again the indices with the best correlations with BHR. In the ICS+ group, the highest correlation coefficients were obtained with mean pre-BD PEFa.m. (0.50), and both minimum and maximum morning pre-BD PEFa.m. (0.49). PEF indices reflecting within-day variation seemed to be suitable as an indicator of BHR in both groups.

\section{Discussion}

This study shows that, in subjects with BHR and reversible airways obstruction, longitudinal correlation coefficients between different PEF indices and BHR are weak to moderate. This applies to patients who are treated with BDs in combination with inhaled corticosteroids and those treated with BDs alone. Indices of diurnal PEF variability calculated with or without post-BD values seem to be the most useful indices for reflecting BHR longitudinally. Cross-sectionally, these indices also correlated well with BHR. Using PEF data that were corrected for the known nonlinearity of mini-Wright PEF meters did not improve the correlation between different PEF indices and BHR.

Guidelines on asthma management recommend the performance of repeated home PEF measurements, being useful for evaluating changes in asthma severity and treatment response. As BHR is a key feature of asthma, it is an important parameter to follow up. It has recently been demonstrated that asthma management plans including BHR

Table 4. - Pearson correlation coefficients for crosssectional relations between peak expiratory flow (PEF) indices and bronchial hyperresponsiveness in subjects treated with bronchodilators (BDs) with (ICS+) or without (ICS-) inhaled corticosteroids after 2 yrs of treatment

\begin{tabular}{lll}
\hline & ICS+ & ICS- \\
\hline Mean pre-BD PEFa.m. & $0.50^{*}$ & 0.25 \\
\% pred & 0.40 & $0.37^{*}$ \\
\% max & 0.42 & $0.40^{* *}$ \\
Min pre-BD PEFa.m. & $0.49^{*}$ & $0.34^{*}$ \\
\% recent best & 0.45 & $0.57^{* *}$ \\
Max pre-BD PEFa.m. & $0.49^{*}$ & 0.15 \\
Mean bronchodilator response & -0.27 & $-0.46^{* *}$ \\
\% mean & -0.43 & $-0.48^{* *}$ \\
\% pred & -0.35 & $-0.42^{* *}$ \\
\% pre-BD PEFa.m. & -0.43 & $-0.47^{* *}$ \\
Mean PEF amplitude (-BD) & & \\
\% mean & $-0.47^{*}$ & $-0.53^{* *}$ \\
\% pred & -0.45 & $-0.53^{* *}$ \\
\% max & $-0.47^{*}$ & $-0.53^{* *}$ \\
Mean PEF amplitude (+BD) & & \\
\% mean & $-0.47^{*}$ & $-0.54^{* *}$ \\
\% pred & -0.44 & $-0.52^{* *}$ \\
\% max & $-0.47^{*}$ & $-0.55^{* *}$ \\
\hline
\end{tabular}

PEFa.m.: morning PEF; \% pred: percentage of the predicted value; max: maximum; min: minimum; amplitude: within-day variation (highest-lowest); -BD: not including post-BD PEFs; $+\mathrm{BD}$ : including post-BD PEFs; *: $\mathrm{p}<0.05$; **: $\mathrm{p}<0.01$. 
are superior to plans without BHR [18]. Although PEF has repeatedly been advocated as proxy for BHR [5], the data to support this notion are scarce. Moreover, there is little clarity as to which PEF index should be used as an indicator of BHR longitudinally. Cross-sectional studies showed that diurnal variability correlated well with BHR $[7,19]$. REDDEL et al. [8] recommended minimum pre-BD PEFa.m. (\%recent best) as the most useful index, because it strongly correlates with BHR in patients with stable asthma and does not require the use of BDs. In the present study, several PEF indices were evaluated with regard to BHR, both longitudinally over a period of 2 yrs and cross-sectionally, in patients treated with BDs with inhaled corticosteroids or without inhaled corticosteroids. All patients showed an increased bronchoconstrictor response to histamine and reversible airways obstruction and can therefore be considered asthmatics.

The present data from cross-sectional analyses, after 2 yrs of treatment, are in accordance with the data of REDDEL et al. [8]. In the present study, minimum pre-BD PEFa.m. (\%recent best) also correlated well with BHR cross-sectionally in all groups, irrespective of medication and irrespective of the prevalence of reversibility at baseline. Cross-sectionally, PEF variability, expressed in terms of within-day variation ( $\%$ mean or $\%$ maximum) (with or without post-BD PEF values), also showed significant correlations with BHR in the two groups. PEF indices reflecting $\mathrm{BD}$ response do not correlate as closely with BHR in patients treated with inhaled corticosteroids as in patients treated without them (table 4). This could be expected as treatment with inhaled corticosteroids improved airways obstruction and, as a consequence, decreased the $\mathrm{BD}$ response in the 33 patients with significant reversibility at baseline [20].

To monitor both asthma severity and treatment response, it is more relevant to know the longitudinal correlation between changes in PEF indices and changes in BHR within patients than the cross-sectional correlations at one point in time within a group. In this study, PEF indices and BHR were evaluated over a period of 2 yrs after starting different treatment regimens. Changes in PEF indices reflecting BD response and within-day variability provided the best correlations with changes in BHR (median $\rho$ $0.50-0.40)$ in the ICS+ group. This group reflects the majority of asthmatic patients seen in clinics. In a similar group of patients (ICS-), the median correlation coefficients were lower, but the same indices showed the best correlations with BHR. Longitudinally, indices based on several measurements a day seem to be more informative (i.e. show a better correlation with BHR) than a single PEFa.m. measure. Unfortunately, these indices are not simple to use in self-management plans. Furthermore, PEF indices reflecting $\mathrm{BD}$ response and indices of within-day variability (with post-BD values) are less useful since, with these indices, patients should use BDs on a regular basis, whereas, in current guidelines on asthma management, short-acting BDs are recommended on demand only.

From this study, it can be concluded that in patients with asthma, mean pre-BD within-day variation in PEF (both \% mean and $\%$ maximum) was the most useful PEF index for reflecting BHR longitudinally. Notwithstanding this, the correlations were still not very strong. Since the correlation coefficient between PEF and BHR longitudinally was maximally 0.5 , it follows that only $25 \%$ of the variability in
BHR is explained by PEF. The authors, therefore, believe that PEF measurements at home have their place and role [6], but not as a proxy for BHR [10].

Since it has been shown that PEF readings are inaccurate in certain flow ranges, it had been hoped that the generally weak correlation coefficients between PEF indices and BHR would improve as a result of correction for this nonlinearity. Unfortunately, there were no differences of any importance in the correlation coefficients.

In conclusion, peak expiratory flow with-day variations (either \% mean or \% maximum) are the most useful peak expiratory flow indices for reflecting bronchial hyperresponsiveness longitudinally in patients with asthma, irrespective of treatment with or without inhaled corticosteroids; however, correlations are modest. Using peak expiratory flow data corrected for the known nonlinearity of miniWright peak expiratory flow meters did not improve the correlations. Cross-sectionally, the same indices can be used, but the minimum prebronchodilator morning peak expiratory flow (\% recent best) is at least as effective and more simple. Since the longitudinally obtained correlation coefficients between peak expiratory flow indices and bronchial hyperresponsiveness are only moderate, the authors suggest that the role of repeated home peak expiratory flow measurements is not suitable as a proxy for changes in bronchial hyperresponsiveness. This statement does not influence the proven usefulness of peak expiratory flow home monitoring in self-management plans $[1,5]$.

The Dutch Chronic Non-Specific Lung Disease (CNSLD) study group. The Dutch CNSLD study group consists of a steering committee (K.F. Kerrebijn, Ph.H. Quanjer, H.J. Sluiter ${ }^{\dagger}$ ), and of members from the departments of pulmonology of the University Hospital of Amsterdam (E.M. Pouw, D.F.M.E. Schoonbrood, C.M. Roos, H.M. Jansen), Groningen (P.L.P. Brand, A. de Gooyer, H.A.M. Kerstjens, D.S. Postma, Th.W. van der Mark, H.J. Sluiter ${ }^{\dagger}$, G.H. Koëter), Leiden (P.M. de Jong, P.J. Sterk, A.M.J. Wever, J.H. Dijkman), Nijmegen (P.N.R. Dekhuijzen, H.T.M. Folgering, C.L.A. van Herwaarden), Rotterdam (S.E. Overbeek, J.M. Bogaard, C. Hilvering) and Utrecht (S.J. Gans, H.J.J. Mengelers ${ }^{\dagger}$, B.A.H.A. van der Bruggen-Bogaarts, J. Kreukniet), the departments of pediatric pulmonology at the Sophia Children's Hospital, Rotterdam (E.E.M. van Essen-Zandvliet, K.F. Kerrebijn), the Juliana Children's Hospital, the Hague (E.J. Duiverman, J.M. Kouwenberg, J.E. Prinsen), University Hospital of Groningen (H.J. Waalkens, J. Gerritsen, K. Knol), the department of allergology, University of Groningen (J.G.R. de Monchy), the department of general practice, Leiden University (F.W. Dekker), the department of psychiatry, University Hospital Leiden (A.A. Kaptein) and the department of physiology, Leiden University (P.J.F.M. Merkus, Ph.H. Quanjer), the Netherlands.

\section{References}

1. Meijer RJ, Kerstjens HAM, Postma DS. Comparison of guidelines and self-management plans in asthma (review). Eur Respir J 1997; 10: 1163-1172.

2. Hetzel MR, Clark TJH. Comparison of normal and asthmatic circadian rhythms in peak expiratory flow rate. Thorax 1980; 35: 732-738. 
3. Cross D, Nelson HS. The role of the peak flow meter in the diagnosis and management of asthma. J Allergy Clin Immunol 1991; 87: 120-128.

4. Lahdensuo A, Haahtela T, Herrala J, et al. Randomized comparison of guided self-management and traditional treatment of asthma over one year. BMJ 1996; 312: 748752.

5. Turner-Warwick M. On observing patterns of airflow obstruction in chronic asthma. Br J Dis Chest 1977; 71: 73-86.

6. National Heart Lung, and Blood Institute, World Health Organization. Global Initiative for Asthma: a Global Strategy for Asthma Management and Prevention. Bethesda, National Institutes of Health, 1995.

7. Ryan G, Latimer KM, Dolovich J, Hargreave FE. Bronchial responsiveness to histamine: relationship to diurnal variation of peak flow rate, improvement after bronchodilator, and airway calibre. Thorax 1982; 37: 423-429.

8. Reddel HK, Salome CM, Peat JK, Woolcock AJ. Which index of peak expiratory flow is most useful in the management of stable asthma? Am J Respir Crit Care Med 1995; 151: 1320-1325.

9. Josephs LK, Gregg I, Mullee MA, Holgate ST. Nonspecific bronchial reactivity and its relationship to the clinical expression of asthma. Am Rev Respir Dis 1989; 140: 350357.

10. Kerstjens HAM, Brand PLP, de Jong PM, Koëter GH, Postma DS, and the Dutch CNSLD Study Group. Influence of treatment on peak expiratory flow and its relation to airway hyperresponsiveness and symptoms. Thorax 1994; 49: 1109-1115.

11. Kerstjens HAM, Brand PLP, Hughes MD, et al. A comparison of bronchodilator therapy with and without inhaled corticosteroid therapy for obstructive airways disease. $N$ Engl J Med 1992; 327: 1413-1419.

12. Miller MR, Dickinson SA, Hitchings DJ. The accuracy of portable peak flow meters. Thorax 1992; 47: 904-909.
13. Miles JF, Tunnicliffe W, Cayton RM, Ayres JG, Miller MR. Potential effects of correction of inaccuracies of the mini-Wright peak expiratory flow meter on the use of an asthma self-management plan. Thorax 1996; 51: 403406.

14. Brand PLP, Quanjer PH, Postma DS, et al. Interpretation of bronchodilator response in patients with obstructive airways disease. The Dutch Chronic Non-Specific Lung Disease (CNSLD) Study Group. Thorax 1992; 47: 429436.

15. Brand PLP, Kerstjens HAM, Jansen HM, Kauffman HF, de Monchy JGR, and the Dutch CNSLD Study Group. Interpretation of skin tests to house dust mite and relationship to other allergy parameters in patients with asthma and chronic obstructive pulmonary disease. $J$ Allergy Clin Immunol 1993; 91: 560-570.

16. Quanjer PH. Standardized lung function testing. Bull Eur Physiopathol Respir 1983; 19 (Suppl. 5): 1-95.

17. Cockcroft DW, Killian DN, Mellon JJA, Hargreave FE. Bronchial reactivity to inhaled histamine: a method and clinical survey. Clin Allergy 1977; 7: 235-243.

18. Sont JK, Willems LN, van Krieken JH, Vandenbroucke JP, Sterk PJ. Clinical control and histopathological outcome of asthma when using airway hyperresponsiveness as an additional guide to long-term treatment. The AMPUL study group. Am J Respir Crit Care Med 1999; 159: 1043-1051.

19. Higgins BG, Britton JR, Chinn S, Cooper S, Burney PGJ, Tattersfield AE. Comparison of bronchial reactivity and peak expiratory flow variability measurements for epidemiologic studies. Am Rev Respir Dis 1992; 145: 588-593.

20. Kerstjens HAM, Brand PLP, Quanjer $\mathrm{PhH}$, van der Bruggen-Bogaarts BAHA, Koëter GH, Postma DS, and the Dutch CNSLD Study Group. Variability of bronchodilator response and effects of inhaled corticosteroid treatment in obstructive airways disease. Thorax 1993; 48: 722-729. 